\section{PSQ-092 PROFILE AND COMPLEXITY LEVEL OF CLINICAL TRIALS IN THE PHARMACY SERVICE}

${ }^{1} R$ Gazquez Perez, ${ }^{1}$ A Alcala Soto*, ${ }^{1} \mathrm{C}$ Puivecino Moreno, ${ }^{2} \mathrm{~L}$ Pichardo Jiménez, ${ }^{1} \mathrm{~A}$ Varas Pérez, 'V Sánchez-Matamoros Piazza, 'JF Sierra Sánchez, ${ }^{1} \mathrm{P}$ Gómez Germá, ${ }^{1} \mathrm{C}$ Mora Herrera, ${ }^{1}$ MT Gómez de Travecedo y Calvo. ${ }^{1}$ Hospital Universitario Jerez de La Frontera, Pharmacy Service, Jerez de La Frontera Cádiz, Spain; ${ }^{2}$ Hospital San Juan Grande, Pharmacy, Jerez de La Frontera Cádiz, Spain

\subsection{6/ejhpharm-2019-eahpconf.525}

Background Pharmacists are involved in critical steps for the performance of clinical trials (CT), such as the reception, dispensing and storage of samples.

Purpose To describe the profile and analyse the complexity level of CT.

Material and methods Descriptive and observational study. CT began in the years 2000-2018 were included. The complexity was assessed according to the classification of Calvin Lamas et al.: low complexity $=6-10$ points, moderate complexity $=11-19$ and high complexity $=20-33$ points. This classification is based on eight items: blinding, number of samples/CT, type of dispensation, number of pharmacy unit professionals involved, use of interactive system (IWRS/IVRS), pharmacy preparation, storage conditions and need for additional conditioning material. The complexity between the two time periods was compared (period 1=2000-2008 versus period 2=2009-2018). The following variables were also collected: name of CT, clinical units, phase, control and randomisation.

Results Two-hundred and four CT were started. There were 120 phase III (58.8\%), 48 phase IV $(23.5 \%)$ and 26 phase II (12.7\%). One-hundred and two CT were no-blind (50\%), 95 were double-blind (46.6\%), five were simple-blind (2.4\%) and two were triple-blind (1\%). 91.2\% CT were randomised and $85.1 \%$ were controlled. The median of samples/CT was $2(0-$ 11). $63.7 \%$ of CT had samples stored at room temperature $\left(15^{\circ} \mathrm{C}-25^{\circ} \mathrm{C}\right), 21.9 \%$ refrigerated $\left(2^{\circ} \mathrm{C}-8^{\circ} \mathrm{C}\right)$ and $14.4 \%$ both type of storage. Preparation under aseptic conditions was required for $20.6 \%$ CT. In $61.4 \%$ CT, the samples were dispensed to the investigator group and in $38.6 \%$ CT were dispensed directly to patients. Clinical units involved: oncology $16.2 \%$, nephrology $15.7 \%$, haematology $14.2 \%$, pneumology $8.8 \%$, infectious disease $7.8 \%$, cardiology $6.9 \%$ and the rest of the units $30.4 \%$. $12.8 \%$ of CT had high complexity, $36.8 \%$ moderate complexity and $50.5 \%$ low complexity. When comparing CT between both periods of time, $59.8 \%$ (67/112) versus $39.1 \%$ (36/92) were low complexity; $31.3 \%$ (35/112) versus $43.5 \%$ (40/92) were moderate complexity; and $8.9 \%(10 / 112)$ versus $17.4 \%$ (16/92) were high complexity; in periods 1 and 2, respectively.

Conclusion The most frequent CT was phase III, no-blind, randomised and controlled. Oncology, haematology and nephrology units performed almost half of the CT during the study period. Period 2 was characterised for having a higher number of high complexity CT.

\section{REFERENCES AND/OR ACKNOWLEDGEMENTS}

https://core.ac.uk/download/pdf/61916246.pdf

No conflict of interest.
5PSQ-093 CHARACTERISATION OF PRE-FILLED SYRINGE USE IN AN ACUTE CARE SETTING: COSTS AND ADVANTAGES

A Harvey*. BD, Health Economics and Outcomes Research, Research Triangle Park- NC27709, USA

\subsection{6/ejhpharm-2019-eahpconf.526}

Background Patient safety in an acute care setting is a high priority, yet medication errors still occur at an alarming rate. Prefilled syringe (PFS) have been shown to reduce adverse medication errors, but they remain poorly adopted for acute care settings - the higher initial cost of PFS possibly being a limiting factor. Exploring the connection between initial cost and cost effectiveness may help highlight overall cost savings in the acute care setting and help bridge the gap to increased patient safety.

Purpose This research aims to review and summarise, for the first time, the literature for PFS drug administration affecting an acute care setting compared to conventional vial/syringe in three key areas: patient safety, supply costs, and time and motion.

Material and methods This work reviewed the current literature to identify cost impact differences between PFS and vials/ampules for cost of supplies, preparation/dosing time, cost per adverse medical event and drug waste across acute care drugs. These findings were summarised to create a resource for acute care settings and help identify areas of greatest impact.

Results The greatest impact on reducing costs lay in a reported aggregate $22.4 \%$ reduction in medication errors when using PFS compared to vials. A reduction was also noted in preparation time between the two methods, resulting in a $49 \%$ reduction in labour costs for PFS. While PFS require fewer administration supplies, the PFS administration cost was reported to be higher than the vial/syringe due to the higher initial device cost. In contrast, one study following operating room drug waste suggested cost parity or potential long-term savings in supply costs when drug wastage is factored in, especially for highcost drugs.

Conclusion PFS have an initial higher cost compared to vial and syringe, but these costs are easily offset in the acute care setting by reducing patient adverse event rates, nursing time and potentially reducing drug waste. With an overall institutional savings for PFS compared to vial and syringe, and increased patient safety, PFS should be an attractive product for acute care settings.

\section{REFERENCES AND/OR ACKNOWLEDGEMENTS}

1. Madziala, M.et al. Pre-filled syringe as an option for drug delivery in emergency medicine. Dis Emerg Med J 2017;2:98-9.

https://www.ncbi.nlm.nih.gov/pubmed/22850220

https://www.ncbi.nlm.nih.gov/pubmed/24991335

https://www.ncbi.nlm.nih.gov/pubmed/24938618

https://www.ncbi.nlm.nih.gov/pubmed/27481691

https://www.ncbi.nlm.nih.gov/pubmed/22918026

Conflict of interest Corporate-sponsored research or other substantive relationships: Becton Dickinson. 